\title{
DAMAGE DETECTION IN LARGE STRUCTURES USING MODES SHAPES AND ITS DERIVATIVES
}

\author{
Shubi Agarwal ${ }^{1}$, Samit Ray Chaudhuri ${ }^{2}$ \\ ${ }^{1}$ Department of Civil Engineering, BITS Pilani Hyderabad Campus \\ ${ }^{2}$ Department of Civil Engineering, IIT Kanpur
}

\begin{abstract}
Synopsis: Many techniques for structural damage detection using modal parameters have been developed over few years because the modal parameters are easily obtained from free, forced and ambient conditions. Many of the techniques have shown that mode shape curvature is efficient to localize damage in continuous system. Focusing on the damage detection/localization of typical Indian Railway bridges, in this paper, a numerical model of an existing steel truss Indian Railway Bridge (discrete system) was developed to check the validity of the mathematical model for continuous shear beam. Numerical model was based on the design drawings of the structure and Eigen value analysis was performed to extract modal parameters. Damage was simulated by modifying the member properties of particular truss members. Results demonstrate that change in fundamental mode shape due damage to a member is an excellent indicator of damage localization because it is discontinuous at damage location. Change in higher derivatives (slope and curvature) of the fundamental mode shape is found to have improved sensitivity in damage localization. These results are similar to those of the shear beams. However, the damage signature is different. Further studies are needed to understand such signatures for meaningful application of the method for existing structures.
\end{abstract}

Keywords: Structural Health Monitoring, Damage Detection, Mode shapes, Bridges.

****

\section{INTRODUCTION}

Large structure such as railway bridges, high-rise building built a long ago loses their strength over the period of time. This is because during this design period, the structure experiences various external disturbances such as strong winds and earthquakes. Structural damage can be defined as any change in the properties of a structural system that can affect the system's performance. As specified in the recent report by IISC ${ }^{[1]}$, on the condition of Indian railway bridges, the damage has been induced even because of increase in the population, increasing the traffic and an increase in design axle load from $18 \mathrm{t}$ to $22 \mathrm{t}$ in the recent years. It is necessary to detect and monitor the condition of the load carrying capacity and strength of the structure to prevent any severe damage to the structure. The collapse or damage especially in the large structure such as bridges can lead to huge losses in terms of life and economy. Thus, all major structures need a continuous monitoring in regular basis to facilitate repairs and rehabilitation whenever required. Monitoring of structure as such is not a new process. In recent years significant studies are being performed to improve the accuracy and reliability of the process, particularly due to advent of modern sensors. In structural health monitoring, vibration-based damage detection techniques are gaining popularity because of their non-destructive nature, accessibility and potential to have a continuous structural health monitoring at an economical cost.

Mode shapes in vibration based damage detection are generally used in structural damage detection and localization because the change in natural frequencies of the vibration of the structure is not very sensitive and accurate. For a continuous structure, the relative displacement at each node for each mode shape is used to identify the change in the shape and curvature of the mode shapes during damage. The mode shape curvature is more sensitive in the localisation of the damage than simple modal displacements. Modes shapes curvature for damage localisation was first proposed by Pandey et al. [2] in which mode shape curvature was shown to be sensitive parameter for damage localization. Mode shape curvature was calculated by the central difference approximation. Sampaio et al. [3] further extended the idea of Pandey et al. [2] by using the curvaturebased method to frequency response function instead of mode shape and demonstrated the potential of this approach by considering real time data. Wahab and Roeck [4] used mode shape curvature for health inspection of a real prestressed concrete bridge structure. Later, Wahab [5] utilized mode shape curvature along with natural frequencies and mode shapes for finite element model updating. Catbas et al. [6] showed the robustness and strength of the flexibility based curvatures using experimental data from a steel grid structure. Ray-Chaudhuri [7] investigated the behaviour of Eigen properties, namely frequencies and mode shapes, in presence of stiffness degradation in simulated structures such as shear building and steel moment-resisting frame (SMRF). Dilena et al. [8] demonstrated that mode shape curvature can be a useful term for damage location on a reinforced concrete single span bridge.

A mathematical formulation with the use of perturbation approach was developed by Roy and Ray-Chaudhuri [9] to inspect the change in frequencies as well as mode shapes for a given location of stiffness degradation in a shear beam. Considering the fundamental mode, the effect of damage was then interpreted with the change in mode shape, slope 
of mode shape, and curvature of mode shape. This approach was shown to be effective for frame building as well [9]. In this work, the approach of Roy and Ray-Chaudhuri [9] has been adopted. The numerical model of Railway Bridge, a discrete system, is modelled with the given design drawings and Eigen value analysis is performed to obtain the modal parameters. This numerical model is used to check the validity of the mathematically formulation of continuous shear beam in a discrete system.

\section{MATHEMATICAL MODELLING:}

The formulation of Roy and Ray-Chaudhuri [9] is presented here for the sake of understanding. Let us consider the case of free vibration of a shear beam with an initial (undamaged) stiffness matrix of $[\mathrm{k}]$. The equations of motion relating the lumped mass matrix ' $\mathrm{m}$ ' and the damaged (reduced) stiffness $[\widehat{\mathrm{k}}]$ can then be expressed in the following [9]:

where $[\hat{\mathrm{k}}]=[\mathrm{k}]+[\Delta \mathrm{k}]$

$$
[\mathrm{m}]\{\ddot{\mathrm{y}}(\mathrm{t})\}+[\hat{\mathrm{k}}]\{\mathrm{y}(\mathrm{t})\}=0
$$

By using the perturbation approach as given by RayChaudhuri [7], the ith damaged mode shape $\widehat{\phi}^{(i)}$ can be related to undamaged mode shape $\phi^{(\mathrm{j})}$ by the following expression:

$$
\widehat{\phi}^{(\mathrm{i})}=\sum_{\mathrm{j}=1}^{\mathrm{n}} \phi^{(\mathrm{j})} \widehat{\Psi}_{\mathrm{ji}}
$$

The stiffness degradation, represented by $\delta \mathrm{k}_{\mathrm{p}}$, takes place in the pth element of the continuous system, the coupling term between damaged and undamaged modes is given by

$$
\widehat{\Psi}_{\mathrm{ji}}= \begin{cases}\frac{\left(\phi_{\mathrm{p}-1}^{(\mathrm{j})}-\phi_{\mathrm{p}}^{(\mathrm{j})}\right)\left(\phi_{\mathrm{p}-1}^{(\mathrm{i})}-\phi_{\mathrm{p}}^{(\mathrm{i})}\right)}{\lambda_{\mathrm{j}}-\lambda_{\mathrm{i}}} \delta \mathrm{k}_{\mathrm{p}}, & \text { for } j \neq i \\ 1 & \text { for } \mathrm{j}=\mathrm{i}\end{cases}
$$

For a uniform shear cantilever beam, the natural frequency and mode shape for the beam of length $\mathrm{L}$ which is modelled as a continuous system for the ith natural frequency is

$$
\begin{aligned}
\omega_{i} & =(2 i-1) \frac{\pi c}{2 L} \\
\phi^{(i)}(y) & =b \sin \left[(2 i-1) \frac{\pi y}{2 L}\right]
\end{aligned}
$$

Let the beam be discretized into $\mathrm{n}$ elements and two consecutive elements are taken to get the difference in the mode shape values. The change between the damaged and undamaged fundamental mode shape $\delta \widehat{\phi}^{(1)}\left(\mathrm{y}_{\mathrm{l}}\right)$ is follows:

$$
\begin{aligned}
& \delta \widehat{\phi}^{(1)}\left(y_{l}\right)=\sum_{j=1}^{n} \frac{\mu}{2 j-1} \sin \left((2 j-1) \frac{\pi}{2 L}\left(y_{1}+y_{p}\right)\right) \\
& +\sum_{j=1}^{n} \frac{\mu}{2 j-1} \sin \left((2 j-1) \frac{\pi}{2 L}\left(y_{1}-y_{p}\right)\right) \\
& -\mu \mathrm{f}\left(\mathrm{y}_{1}\right) \\
& \mathrm{f}\left(\mathrm{y}_{\mathrm{l}}\right)=2 \sin \left(\frac{\pi \mathrm{y}_{\mathrm{l}}}{2 \mathrm{~L}}\right) \cos \left(\frac{\pi \mathrm{y}_{\mathrm{p}}}{2 \mathrm{~L}}\right) \\
& \mu=\frac{\mathrm{b}^{3} \epsilon^{2}}{2 \mathrm{c}^{2}} \cos \left(\frac{\pi \mathrm{y}_{\mathrm{p}}}{2 \mathrm{~L}}\right) \delta \mathrm{k}_{\mathrm{p}}
\end{aligned}
$$

The second term converges $\pi / 4$ so the general equation for the change comes out to be as follows:

$$
\delta \widehat{\phi}^{(1)}\left(\mathrm{y}_{1}\right)= \begin{cases}\mu\left[\frac{\pi}{2}-\mathrm{f}\left(\mathrm{y}_{1}\right)\right]: & \mathrm{y}_{1}>\mathrm{y}_{\mathrm{p}} \\ \mu\left[\frac{\pi}{4}-\mathrm{f}\left(\mathrm{y}_{1}\right)\right]: & \mathrm{y}_{1}=\mathrm{y}_{\mathrm{p}} \\ \mu\left[-\mathrm{f}\left(\mathrm{y}_{1}\right)\right]: & \mathrm{y}_{1}<\mathrm{y}_{\mathrm{p}}\end{cases}
$$

From the equation we can interpret that the function has a jump between the element yp +1 and yp- 1 which means there is a zero crossing at that particular point. The first derivative of the difference gives us that there will be a sudden slope change in the yp. The second derivative of this again shows the function has a jump between the element yp+1 and yp-1 which means there is a zero crossing. All these results have been verified by numerical modelling for the continuous system. In this we will be verifying the above theory and formulation for a discrete system as a bridge in this case.

\section{NUMERICAL MODELLING:}

In this, to demonstrate the validity of the above proposed theory for a large bridge structure, a model of Indian Railway Bridge (Chambal Bridge) is taken. The bridge was modelled to use and perform modal analysis. Being a large structure, it is impossible to detect damages by visual analysis, there is a need to develop large scale global technique to localise the damage in the structure. To identify the signature, model has been created to understand the behaviour and to be able to predict the damage in the real structure.

The bridge is a steel truss Railway bridge consisting of 10 spans. Each span rests of two RCC piers, so there is a total of 11 piers. In this, one span of the bridge is modelled using commercial finite element software SAP 2000. The actual length of one span of the bridge is $78800 \mathrm{~mm}$ and the effective length is $76820 \mathrm{~mm}$. Each element in the finite element modelling is of the length $7880 \mathrm{~mm}$. It is divided into 10 such elements for the analysis. The ends or the boundary conditions are assumed to be fixed-fixed at all four edges. The material of the bridge is mild steel. The breadth and height of the bridge are $6500 \mathrm{~mm}$ and 10500 $\mathrm{mm}$ respectively. 


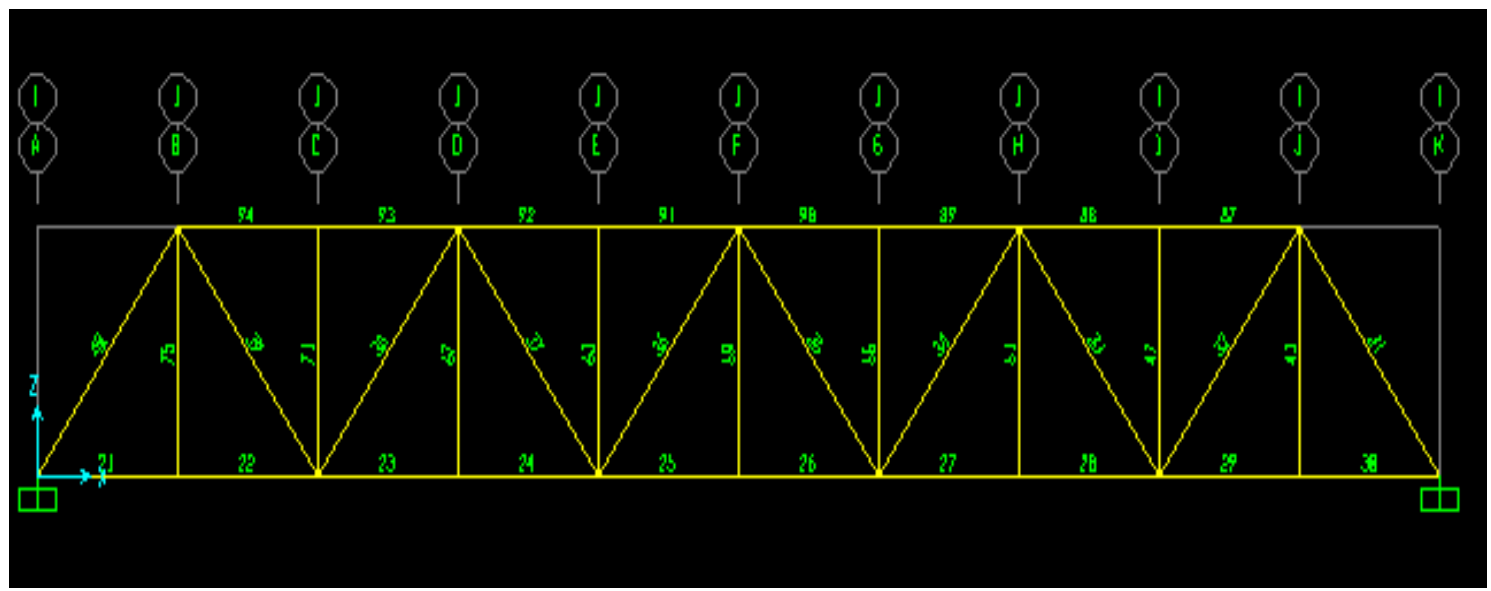

Figure 1 : Front view of the bridge modelled in SAP 2000 with numbering

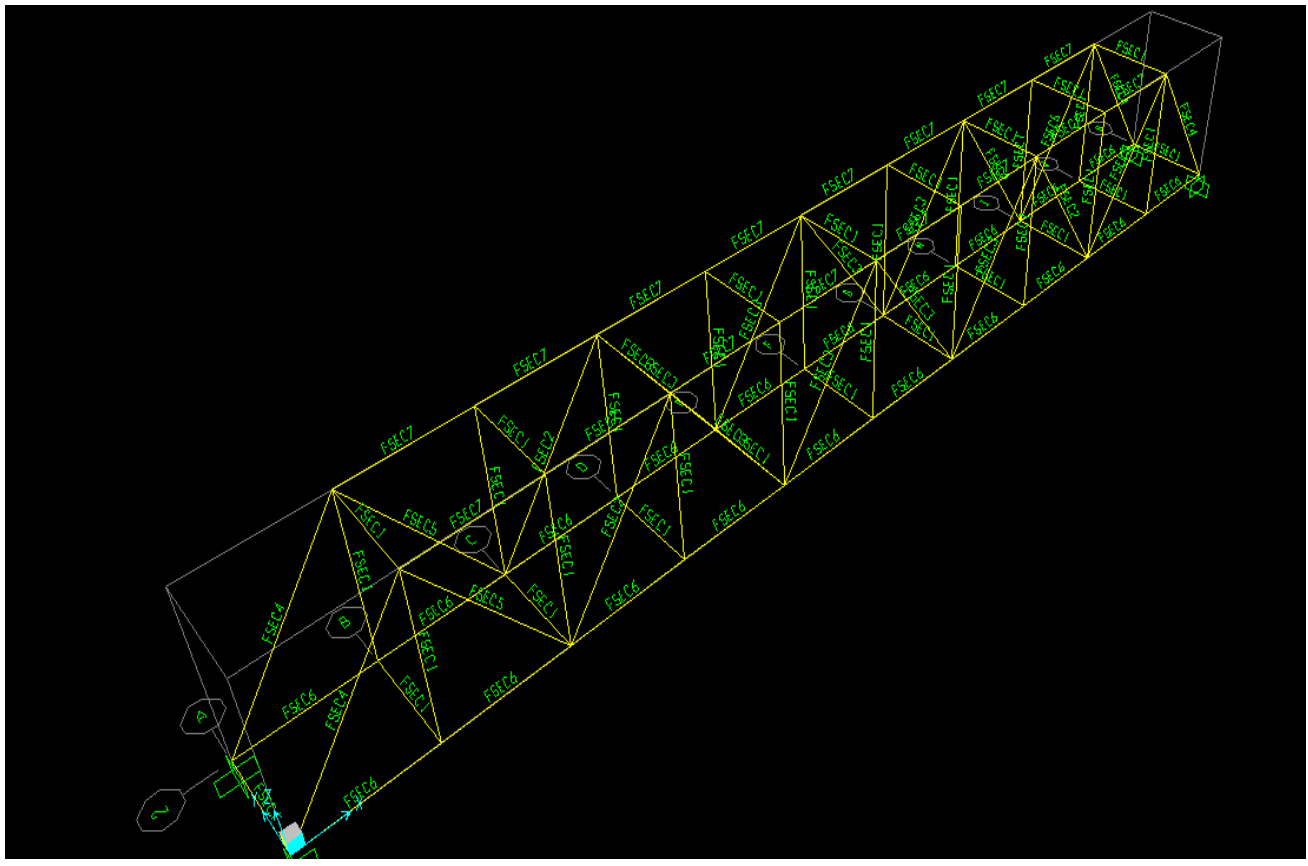

Figure 2 : 3-D view of the bridge modelled in SAP 2000 with the section labels

There are 7 different built up sections used to model the bridge with varying combinations of plates, lacing and angle sections. These sections differ according to position in the bridge depending on the strength needed at the particular position.

\begin{tabular}{|c|c|}
\hline \multicolumn{2}{|c|}{ Table 1 : Section details of the bridge } \\
\hline SECTION NO. & DETAILS \\
\hline FSEC 1 & 4 Ls 125x75x10 mm, 1 WEB PLs 370x8 mm \\
\hline FSEC 2 & 4 Ls 150x75x10 mm, 2 side PLs 500x10 mm, lacing flat 65x10 mm \\
\hline FSEC 3 & 4 Ls 90x90x10 mm, 2 side PLs 400x10 mm, lacing flat 65x10 mm \\
\hline FSEC 4 & 4 Ls 150x115x12 mm, 2 side PLs 630x12 mm, 2 ADDLs 330x12 mm, 1 TOP FL PL \\
\hline FSEC 5 & 4 Ls 150x75x10 mm, 2 side PLs 500x16 mm, batten PLs 210x10x370 mm \\
\hline FSEC 6 & 4 Ls 150x115x10 mm, 2 side PLs 630x25 mm, 2 ADDLs 330x10 mm \\
\hline FSEC 7 & mm, LACING Ls 75x75x8 mm \\
\hline
\end{tabular}


The model in SAP 2000 is given a load of $9.88 \mathrm{KN} / \mathrm{mm}$ as given by the calculation previously done, which basically includes the dead weight of the rail track. Modal analysis (Eigen value) is performed for the system. The modal displacements and the frequencies for each of the mode shapes are obtained from the modal analysis. All the modal displacement values are tabulated for the analysis. This set of data so obtained is in undamaged state. The modal displacements along $\mathrm{X}$-axis, $\mathrm{Y}$-axis and $\mathrm{Z}$-axis of the first mode are taken in this to verify the theory of damage detection proposed by Roy and Ray-Chaudhuri [9].

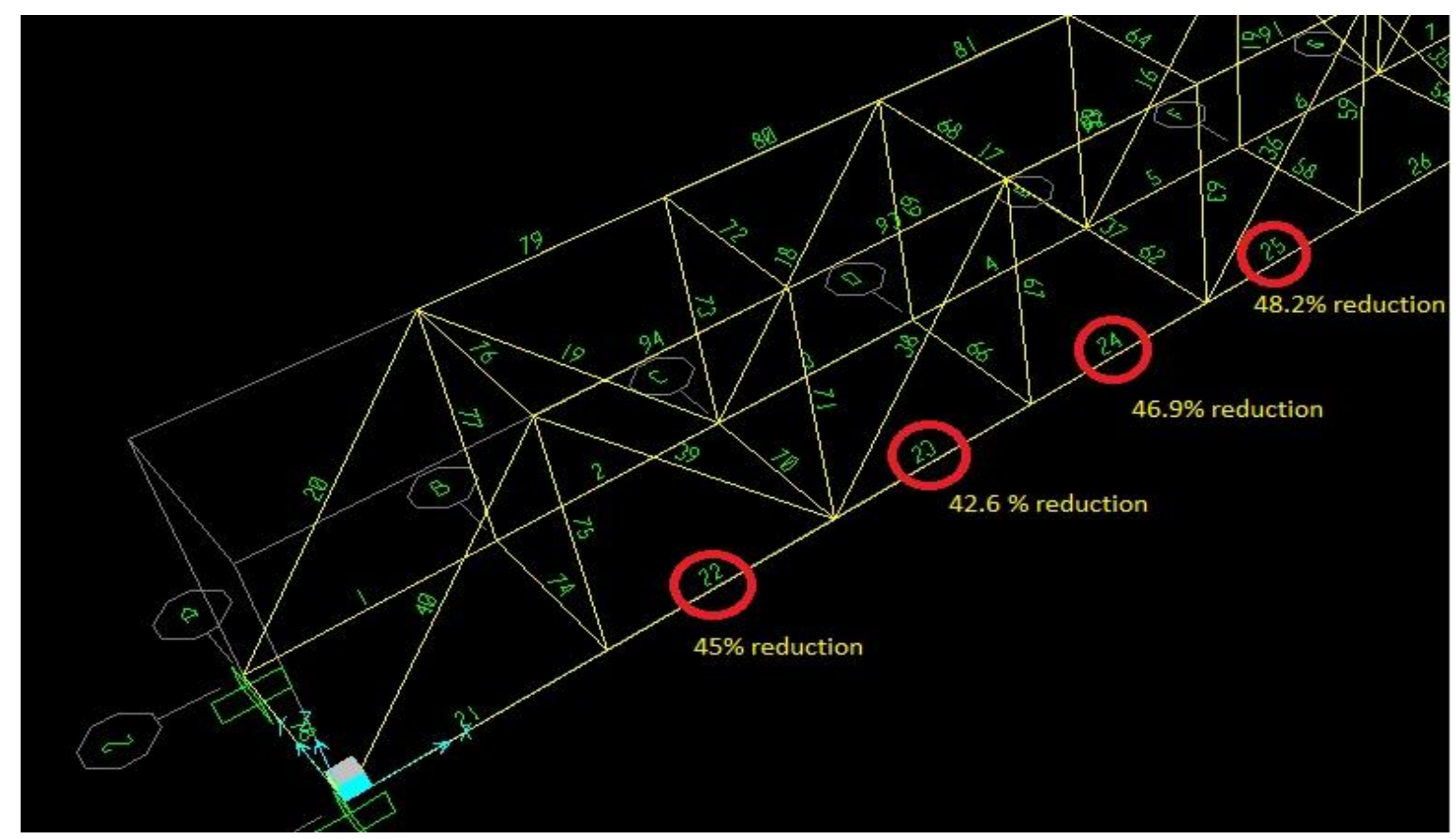

Figure 3 : Damage is introduced along the $\mathrm{X}$-axis in the elements 22, 23, 24 and 25

The damage is introduced in the structure by reduction in the area of cross section of various members at various positions. The area is reduced by approximately 40 to $50 \%$.

For the analysis, at first the modal displacement of both undamaged and damaged values for each of the four conditions of damage mode shapes is plotted against distance along the $\mathrm{X}$-axis. Second, the change in displacement is the plotted against distance. Third, the slope of the change in displacement in the mode shapes which the first derivative, is found using central approximation, of the previous function is plotted against the distance. Last, the curvature of the change in displacement in the mode shapes, which is the second derivative of the change in displacement, found by central approximation, is plotted against the distance. The displacements and distance used above are all normalised values. The values are normalised for the reason to avoid any deviation in the results due to signs.

\section{RESULTS}

The graphs are plotted to understand the results obtained and to localise the damage accordingly. The graphs are plotted for elements $22,23,24$ and 25 along the three axes. In the figure 4, results of the element 25 are shown. The top-left corner graph shows the undamaged and damaged mode shapes. This graph does not help to localise the damage as there is no significant feature observed. The top right graph shows the change in the mode shape and as we see there is sudden change in the displacement value i.e. there is a zero crossing as predicted by the mathematical formulation. The bottom left graph shows the slope of the change in mode shape and as stated by the theory there is a steep slope change at the damage location. The bottom right graph shows the curvature of change in the mode shape and verifies the theory stated having a zero crossing at the damage location.

Similar results are obtained for the elements 22, 23 and 24. From the results above for the mode 1 along $\mathrm{X}$-axis, for change and curvature of the change between damage and undamaged, there is a zero crossing at the distance of the damage element and the first derivative has a sharp change in slope is observed at the damage location. These are the signature so obtained and there is a consistency in the results for all the four elements in which damage is introduced and they are in line with the theory given for the continuous shear beam. 

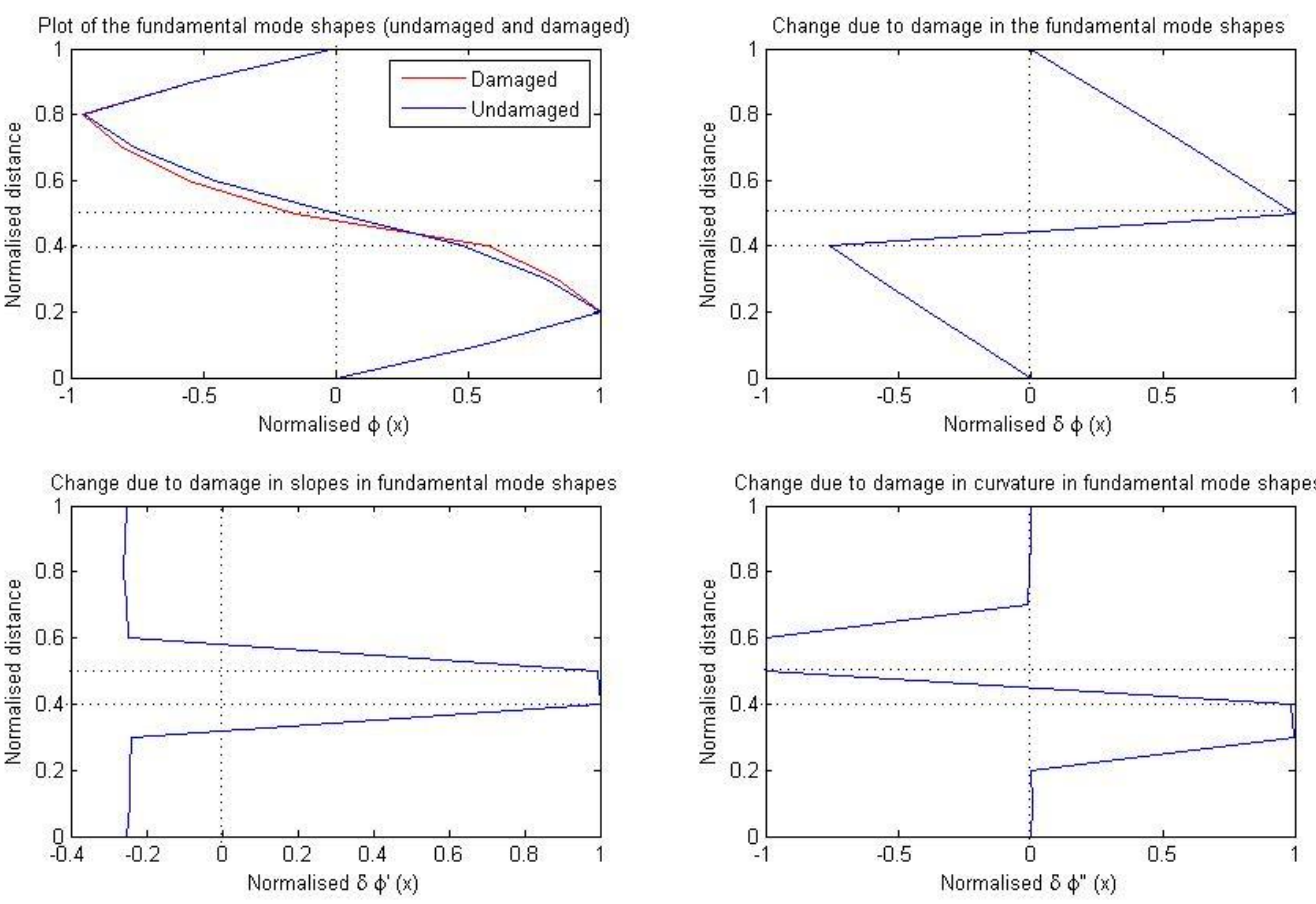

Figure 4 : Analysis results of element 25 along X-axis

The graphs obtained for introduction of the damage in the element 25 the mode shape along the Y axis. In the figure 5, the top-left corner graph shows the undamaged and damaged mode shapes. This graph does not show any localisation of the damage as there is no significant feature observed. The top right graph shows the change in the mode shape and as we see there is sudden change in the slope of the graph at the damage location. The bottom left graph shows the slope of the change in the mode shape and there is a change in the displacement value i.e. there is a zero crossing at the damage location. The bottom right graph shows the curvature of change in the mode shapes, there is sudden change in the slope of the graph at the damage location.
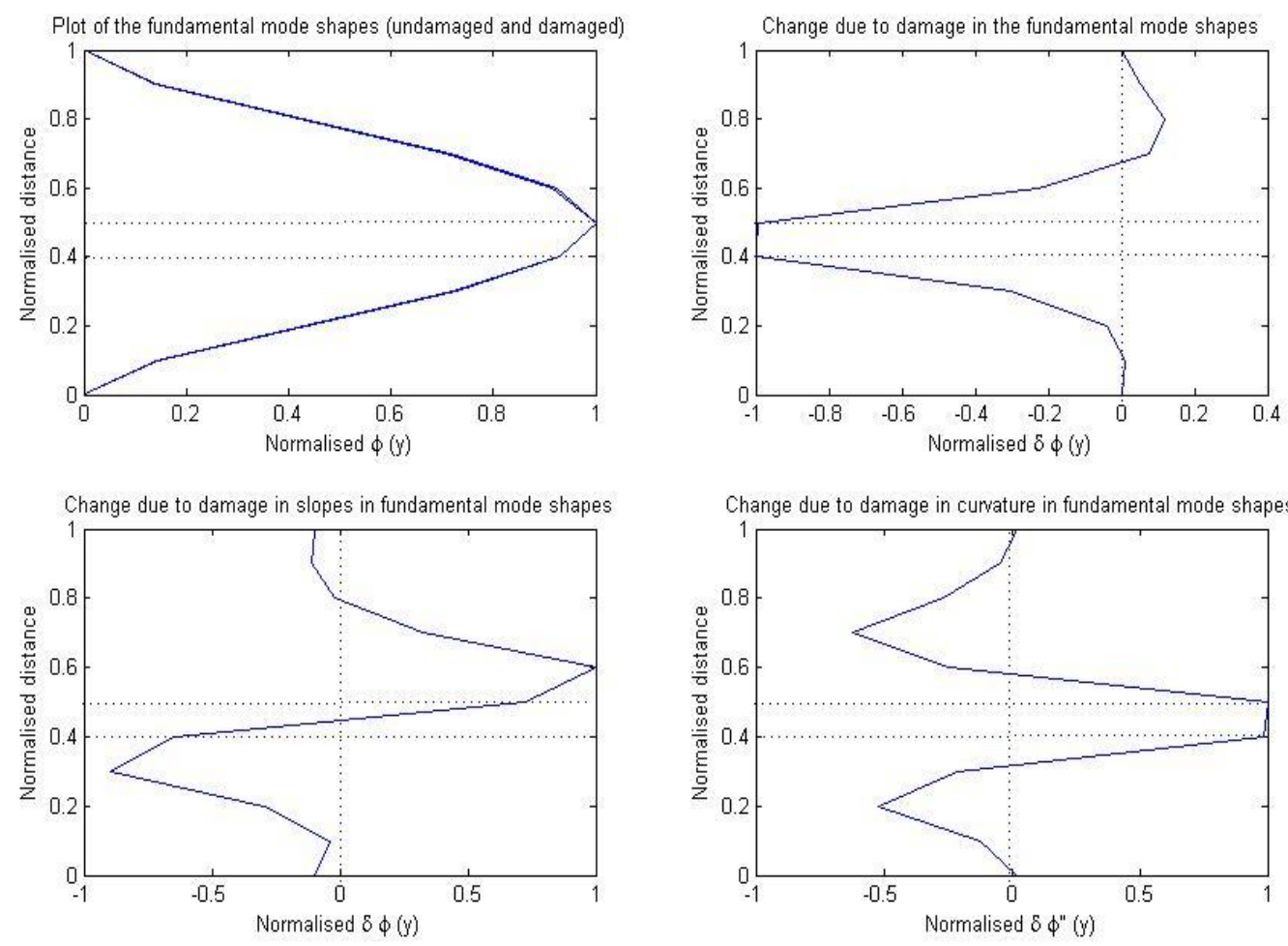

Figure 5 : Analysis results of element 25 along Y-axis 
The result obtained for the elements 22,23 and 24 are similar to that obtained for element 25 . The consistencies in the results give the signature for localisation of damage and verify the results. Thus, the signature for the damage localisation along the $\mathrm{Y}$-axis is obtained from the results.

The result for the damage localisation of element 25 along $\mathrm{Z}$-axis mode 1 , the element is shown. In the figure 6 , the top-left corner graph shows the undamaged and damaged mode shapes. This graph does not show any localisation of the damage as there is no significant deviation observed. The top right graph shows the change in the mode shape and as we see there is sudden change in the slope, though not significant in the graph at the damage location. The bottom left graph shows the slope of the change in the mode shape and there is a sudden change in the displacement value i.e. there is a zero crossing at the damage location. The bottom right graph shows the curvature of change in the mode shapes, there is sudden change in the slope of the graph at the damage location which is again not prominent.
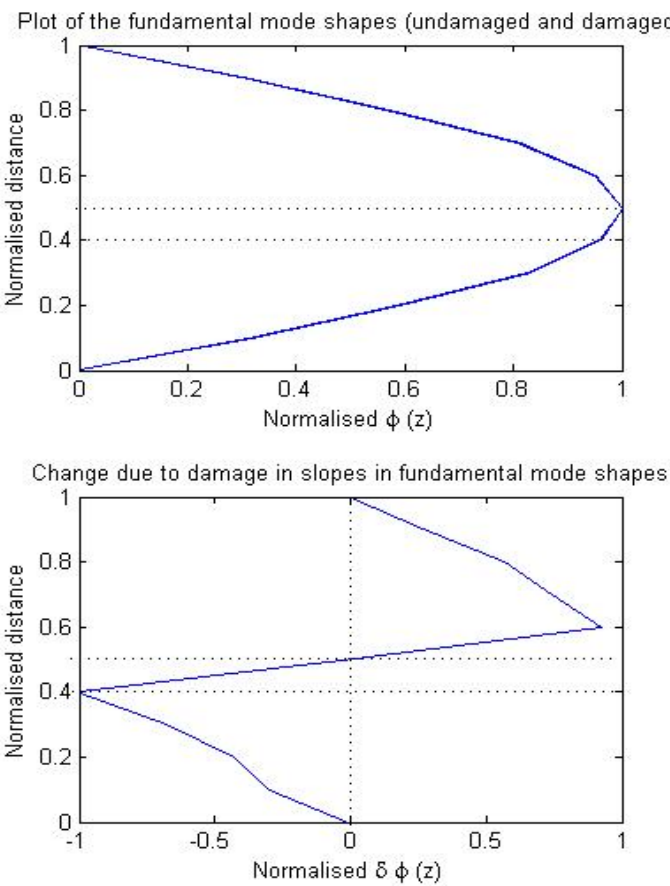

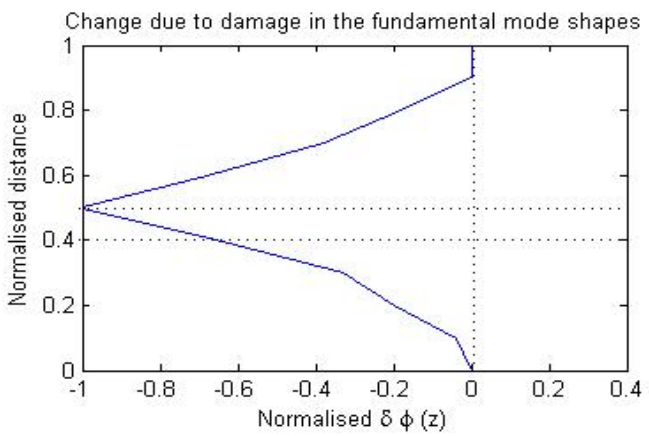

Change due to damage in curvature in fundamental mode shapes

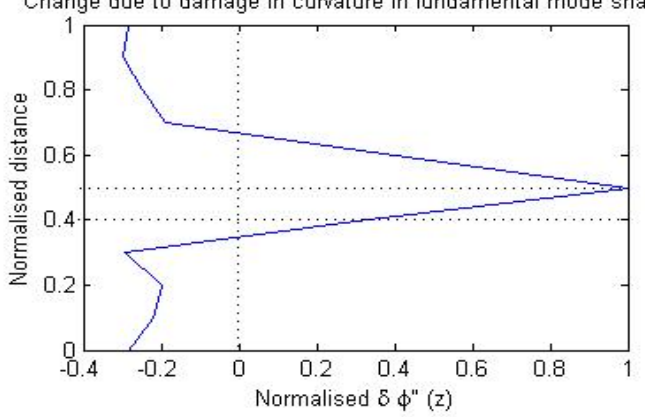

Figure 6 : Analysis results of the element 25 along the Z-axis

Similar results are obtained for the element 22, 23 and 25; therefore the generalisation can be done for the signature of the mode 1 shape along the $\mathrm{Z}$-axis, for the damage localisation.

\section{DISCUSSIONS :}

The results obtained are for mode 1 along the three axes for 4 cases of the damage introduced in the system to check for the signature and understand the theory behind those results. From the results obtained, various points can be generalised for mode shape along various directions.

Along the $\mathrm{X}$-axis the results so obtained are similar to that of the continuous shear beam. This is so because along the for the mode shape along the $\mathrm{x}$-axis is same as the continuous beam being discretized into finite number of elements for the modal displacement to draw out the mode shape. Therefore, the results obtained can be justified by the theory given for the continuous beam.

Along the $\mathrm{Y}$-axis the results are the reverse to that given by the theory. Though, the damage can still be localised as there is sudden slope change in the curvature of the change in mode shape and there is a zero crossing in the slope of the change in mode shapes. Therefore, mathematically formulation is needed to get the signatures along this direction for developing a damage detection system.

Along the Z-axis the results are similar to that as observed for the $\mathrm{Y}$-axis. The results are reversed as stated by the theory. This is because this is a discrete system and the mathematically formulation stated is for a continuous shear beam. Therefore, a theory needs to be developed for getting the signatures of the damages.

The numerical development in this has many assumptions. This is performed in ideal conditions, where we can obtain free vibration response for the analysis. The accurate result can only be obtained in the case of free vibration response. But in actuality, it is not possible to isolate the system from the surrounding influence. The most of the readings are taken in ambient conditions. Some measurement techniques are developed to take in the ambient condition response and separate the free vibration from it. We generally tend to use output only measurement because it is not possible to get the input ambient vibrations. The various techniques developed are: 
$>$ Frequency Domain Decomposition (FDD), as proposed by Brincker et al. [10], is a frequency domain system identification technique based on singular value decomposition (SVD) of power spectral density (PSD) of the responses. This algorithm is widely applied on ambient response analysis of buildings [11], bridges [12], vehicles [13], etc. Therefore, FDD depicts its versatile efficacy with its broader domain of applicability.

$>$ Natural Excitation Technique (NExT) with EigenSystem Realization Algorithm (ERA) is a popular approach for the identification of modal parameters as it is a robust technique. At first, NExT is employed to find out the free vibration response from ambient response assuming the input excitation as white noise. After that, ERA, proposed by Juang and Pappa [14], is used to extract the modal parameters from free vibration response. Chiang et al. [15] developed a modified form of ERA for modal parameter identification using ambient data. NExT-ERA has also been applied as an output-only technique for health monitoring as well as damage detection of suspension bridges [16] simulated IASC-ASCE benchmark building [17], etc

$>$ Random Decrement Technique (RDT) is a popular method to extract the free vibration response from structural ambient response. Ibrahim [18] proposed this time domain technique to extract free vibration response of a structure from its ambient response. This technique is usually used as a harmonic elimination algorithm [19] and operational modal analysis in the presence of periodic excitations [20]

$>$ Autoregressive Model is a linear prediction model which has a feature of predicting future data of a given signal based on its previous obtained data. The parameters such as coefficients and residual error of the model are the function of the properties of the response signal and the structure itself. The measure of standard deviation of the residual error plays a major role in identifying the location of damage. Lu and Gao [21] proposed this efficient time-domain technique based on autoregressive prediction model for structural damage localization. This approach is found to be equally efficient on simulated bridge model [22], experimental model of steel frame structure [23], and real bridge structure [24].

Civil engineering structures are generally large, so it is impossible to isolate the system for obtaining the accurate values without some amount of it mixed with noise. This is where these techniques come in use to getting better results.

\section{CONCLUSIONS}

Damage detection and structural health monitoring are the need of the hour as evident from the vast amount of research carried out recently. The methods developed basically aim on achieving accessible and reliable approach which can be globally used for damage detection. Vibration-based methods are being popularised for many of their advantages over other methods. These techniques depend on mode shape and frequency of the system. Mode shape is preferred over natural frequency because of its sensitivity to damage giving better localization results. By the mathematical model, it has shown that the curvature of change in mode shape is the most accurate in damage detection and localisation as it gives a zero crossing or sudden displacement value change at the damage location. This model given is verified for a continuous shear beam. In this study, effort has been given to verify the above theory for steel truss bridge. A numerical model of steel bridge structure is taken and modelled in finite element software. The results for the mode shapes along $\mathrm{X}$-axis, $\mathrm{Y}$-axis and $\mathrm{Z}$ axis for fundamental mode are taken. On analysis, it is found that the results along $\mathrm{X}$-axis exactly tally with the theory given for the continuous beam as long as that axis is the system of a continuous beam. But results of the $\mathrm{Y}$-axis and Z-axis show opposite observation. Though specific signatures are observed for damage detection, a generalised theory is needed. Also, these results are obtained considering ideal conditions. In real time, there is a lot of disturbance by the surrounding conditions. So there is a need to obtain free vibration response from the measurement under ambient conditions. Various techniques are developed for this, such as Frequency Domain Decomposition, Random Decrement Technique, etc. Further research (theoretical as well as experimental) is needed to verify the applicability of these techniques.

\section{ACKNOWLEDGEMENTS:}

I would like to thank the Civil Engineering Department, IIT Kanpur for providing me with the resources and inputs needed throughout the study.

\section{NOTATIONS:}

$\widehat{\psi}_{j i} \quad$ Coupling term between the damage and

undamaged mode shapes.

$\widehat{\phi}^{(i)} \quad$ ith damaged orthogonal mode shape

$\mathrm{y}_{\mathrm{p}} \quad$ Particular damage location

$\lambda_{\mathrm{i}} \quad$ Square of the ith undamaged natural frequency

$\omega_{\mathrm{i}} \quad$ ith undamaged natural frequency

$\phi^{(\mathrm{j})} \quad$ Undamaged orthogonal mode shape

$\phi_{\mathrm{p}}^{(\mathrm{i})} \quad$ pth element of the ith damaged mode shape

$\phi_{\mathrm{p}}^{(\mathrm{j})} \quad$ pth element of the jth undamaged mode shape

$\phi_{\mathrm{p}-1}^{(\mathrm{i})} \quad(\mathrm{p}-1)$ th element of the ith damaged mode shape

$\phi_{\mathrm{p}-1}^{(\mathrm{j})} \quad(\mathrm{p}-1)$ th element of the $\mathrm{jth}$ undamaged mode shape

$\Delta \mathrm{k} \quad$ Change in the stiffness.

b Constant governed by L and mass per unit length

( $\rho)$ of the beam

c Shear wave velocity 
k Stiffness

L Length of the beam

m mass

$\delta \widehat{\phi}^{(1)}$ difference between undamaged and damaged

fundamental mode shape

$\delta \mathrm{k}_{\mathrm{p}} \quad$ Stiffness degradation

$\delta \mathrm{k}_{\mathrm{p}} \quad$ Severity of stiffness degradation

\section{REFERENCES:}

[1] IISC, " Condition assessment of railway Bridges", 2010,URL: civil.iisc.ernet.in/crbridge.pdf

[2] A. K. Pandey, M. Biswas, and M. M. Samman., "Damage detection from changes in curvature mode shapes", Journal of Sound and Vibration, Elsevier, 145(2), 1991, pp. 321-332.

[3] R.P.C. Sampaio, N.M.M. Maia, and J.M.M. Silva.," Damage detection using the frequency-responsefunction curvature method", Journal of Sound and Vibration, Elsevier, 226(5), 1999, pp. 1029-1042.

[4] M.M.A.Wahab, G.D.Roeck. "Damage detection in bridges using modal curvatures: application to a real damage scenario", Journal of Sound and Vibration, Elsevier, 266, 1999, pp. 217-235.

[5] Wahab., M. M. A. "Effect of modal curvatures on damage detection using model updating",Mechanical Systems and Signal Processing, Elsevier, 15(2), 2001, pp 439-445.

[6] F.N.Catbas, M.Gul, J.L.Burkett. "Damage assessment using flexibilty and flexibility-based curvature for structural health monitoring", Smart Materials and Structures, Elsevier, 17(1), 2008, pp. 1524.

[7] Ray-Chaudhuri., S. "Change in instantaneous eigenproperties due to yielding of a structure.", Journal of Sound and Vibration, Elsevier, 312(4-5), 2008, pp. 754-768.

[8] M.Dilena, A.Morassi, M.Perin. "Dynamics identification of a reinforced concrete damaged bridge.", Mechanical Systems and Signal Processing, Elsevier, 25(8), 2011, pp. 2990-3009.

[9] K.Roy, S.Ray-Chaudhuri. "Fundamental mode shape and its derivatives in structural damage localisation", Journal of Sound and Vibration, Elsevier, 332, 2013, pp. 5584-5593.

[10] Brincker R and Anderson PBrincker R, Zhang L, and Andersen P. "Modal identification of output-only systems using frequency domain decomposition. ", Smart Materials and Structures, Elsevier, 10(3), 2001, pp. 441.

[11]P., Brincker R and Anderson. " Ambient resopnse analysis of the heritage court tower building structure", In Proceedings of 18th International Modal Analysis Conference, 2000.

[12] Brincker R, Frandson JB, and P. Andersen. " Ambient response analysis of the great belt bridge", In
Proceedings of 18th International Modal Analysis Conference 2000

[13] Brincker R, Andersen P, and Moller N "Output-only modal testing of a car body subject to engine excitation" In Proceedings of the International Modal Analysis Conference IMAC., 2000, pp. 786-792.

[14]RS., Juang JN and Pappa. "An eigensystem realization algorithm for model parameter identification and model reduction. ", Journal of Guidance, Control, and Dynamics, Elsevier, 8(5), 1985, pp. 620-627.

[15] Chiang DY, Lin CS, and Su FH. "Identification of modal parameters from ambient vibration data by modified eigensystem realization." Journal of Aeronautics, Astronautics and Aviation, Elsevier, Series A, 42(2), 2010, pp. 79-86.

[16]Y., Siringoringo DM and Fujino. "System identification of suspension bridge from ambient vibration response,. Engineering Structures, Elsevier, 30(2), 2008, pp. 462-477.

[17] Lin S, Yang JN, and Zhou L. "Damage identification of a benchmark building for structural health monitoring", Smart Materials and Structures, Elsevier, 14(3), 2005, pp. 162-169.

[18] SR., Ibrahim. "Random decrement technique for modal identification of structures." , Journal of Spacecraft and Rockets, Elsevier, 14, 1977, pp. 696-700.

[19]Modak SV, Rawal C, and Kundra TK.x. "Mechanical Systems and Signal Processing." Mechanical Systems and Signal Processing, Elsevier, 24(4), 2010, pp. 922-944.

[20] Asayesh M, Khodabandeloo B, and Siami A. "A random decrement technique for operational modal analysis in the presence of periodic excitations". Part C: Journal of Mechanical Engineering Science, Elsevier, 223(7), 2009, pp. 1525-1534.

[21]F, Lu Y and Gao. " A novel time-domain autoregressive model for structural damage diagnosis", Journal of Sound and Vibration, Elsevier, 283, 2005, pp. 1031-1049.

[22] Terrell T, Gul M, and Catbas FN. Jacksonville, FL, "Structural health monitoring of a bridge model using ARX models." In Conference Proceedings of the Society for Experimental Mechanics Series. Vol. 4, 2011, pp. 357-364.

[23] Zhang N, Wei ZB, and Wu S. "Experimentation study of damage identification for steelframe structure based on ar model. " Conference of 2nd International Conference on Mechatronics and Intelligent Materials. , 2012.

[24] FN.., Gul M and Catbas. "Damage detection using a novel time series methodology: Application to the z24 bridge data. Philadelphia, PA ". In Bridge Maintenance, Safety, Management and Life-Cycle Optimization - Proceedings of the 5th International Conference on Bridge Maintenance, Safety and Management, 2010. 